\title{
DOI: https://doi.org/10.24297/jam.v16i0.8169
}

\section{Comparison of Halley-Chebyshev Method with Several Nonlinear equation Solving Methods Methods}

\author{
Hamideh Eskandari \\ Payame Noor University, Department of Mathematics, I.R. Iran \\ h_eskandari@pnu.ac.ir
}

\begin{abstract}
In this paper, we present one of the most important numerical analysis problems that we find in the roots of the nonlinear equation. In numerical analysis and numerical computing, there are many methods that we can approximate the roots of this equation. We present here several different methods, such as Halley's method, Chebyshev's method, Newton's method, and other new methods presented in papers and journals, and compare them. In the end, we get a good and attractive result.
\end{abstract}

Keywords: Converge, Newton Method, Halley Method, Chebyshev Method, Nonlinear Equation, Hybrid Method, Steffenson Method.

\section{Introduction}

One of the most important problems in Numerical Analysis is finding different values of the $x$ variable in the $f(x)=0$ equation that there exist variate methods for solution and it exist in [1], [2], [6], [8], [9] and [10]. Mostly this equation is solved by the Newton iteration method, that is

$$
x_{n+1}=x_{n}-\frac{f\left(x_{n}\right)}{f^{\prime}\left(x_{n}\right)}
$$

It is known that Newton method has the convergence of the second order term. However, in the method which is mentioned here, the convergence is of higher order term. In fact, this new method is more convergent than the other methods, that is, the Newton method and the hybrid method [7] and Fang [5] and new method [3] and et cetera.

\section{Several methods for equation solution}

A new iteration method based on Taylor theorem was proposed to solve nonlinear algebraic equations by Nasr [7]. It is claimed that this new method has better convergent characteristics than the well-known Newton method. This method has iteration formula like below formula

$$
x_{k+1}=\frac{-B \pm \sqrt{B^{2}-4 A C}}{2 A}
$$

Where $A=f^{\prime \prime}\left(x_{k}\right), B=6 f^{\prime}\left(x_{k}\right)-2 f^{\prime \prime}\left(x_{k}\right) x_{k}$ and $C=6 f\left(x_{k}\right)-6 f^{\prime}\left(x_{k}\right) x_{k}+f^{\prime \prime}\left(x_{k}\right) x_{k}^{2}$.

The other method that here oppugn is Halley method [11]. This method has iteration formula too

$$
x_{n+1}=x_{n}-\frac{f\left(x_{n}\right) f^{\prime}\left(x_{n}\right)}{\left(f^{\prime}\left(x_{n}\right)\right)^{2}-\frac{1}{2} f\left(x_{n}\right) f^{\prime \prime}\left(x_{n}\right)}
$$


The next method is Chebyshev method [12] and we have

$$
x_{n+1}=x_{n}-\left(1+\frac{1}{2} \frac{f^{\prime \prime}\left(x_{n}\right) f\left(x_{n}\right)}{\left(f^{\prime}\left(x_{n}\right)\right)^{2}}\right) \frac{f\left(x_{n}\right)}{f^{\prime}\left(x_{n}\right)}
$$

Another method that it is new method and we named that Halley-Chebyshev method [4] is

$$
x_{n+1}=x_{n}-\left(\omega \frac{f\left(x_{n}\right) f^{\prime}\left(x_{n}\right)}{\left(f^{\prime}\left(x_{n}\right)\right)^{2}-\frac{1}{2} f\left(x_{n}\right) f^{\prime \prime}\left(x_{n}\right)}+(1-\omega)\left(1+\frac{1}{2} \frac{f^{\prime \prime}\left(x_{n}\right) f\left(x_{n}\right)}{\left(f^{\prime}\left(x_{n}\right)\right)^{2}}\right) \frac{f\left(x_{n}\right)}{f^{\prime}\left(x_{n}\right)}\right)
$$

Where $\omega$ is an arbitrary parameter and $0 \leq \omega \leq 1$.

And the last method that we have too is Steffenson method [1] and we have iteratin formula

$$
x_{n+1}=x_{n}-\frac{\left(f\left(x_{n}\right)\right)^{2}}{f\left(x_{n}+f\left(x_{n}\right)\right)-f\left(x_{n}\right)}
$$

\section{Comparison of several methods with example}

In this section we perform some numerical examples using our new methods and we will compare these results to famous methods. All computations were done MAPLE. We know that an approximate solution rather than the accurate root, depending on the precision $(\varepsilon)$ of computer. We use the following stopping test for computer programs: (i) $\left|\mathrm{x}_{\mathrm{n}+1}-\mathrm{X}_{\mathrm{n}}\right|<\varepsilon$, (ii) $\left|\mathrm{f}\left(\mathrm{x}_{\mathrm{n}+1}\right)\right|<\varepsilon$.

In here, we have real several methods of non-linear equation that we compare them with together in tables.

\section{Example1}

Consider the equation $f(x)=\left(x^{2}-5 x+7\right) e^{x}+x-3$. This function has a single root with accurate amount -1.248014042 . In order to find a root close to $x=-1.248014042$, we let $x_{0}=1$. The obtained results by Newton iteration, new hybrid iteration [3], and Halley method [11] are presented in the under table. (Table 1 with $\varepsilon=10^{-100}$ )

\section{Table 1}

\begin{tabular}{lcc}
\hline Methods & $\begin{array}{c}\text { The numbers of } \\
\text { iterations }\end{array}$ & $\begin{array}{c}\text { approximate } \\
\text { solution }\end{array}$ \\
\hline Newton method [1], [2], [6], [8], [9] and [10] & 9 & -1.248014041 \\
\hline Hybrid method [7] & 5 & -1.248014038 \\
\hline New Hybrid method [3] with $\omega=0$ & 4 & -1.248014040 \\
\hline
\end{tabular}




\begin{tabular}{lcc}
\hline New Hybrid method [3] with $\omega=0.35$ & 5 & -1.248014040 \\
\hline Chebyshev method [12] & 9 & -1.248014042 \\
\hline Halley method [11] & 5 & -1.248014041 \\
\hline Steffenson method [1] & 233 & -1.248014042 \\
\hline Halley-Chebyshev method [4] with $\omega=0.35$ & 6 & -1.248014041 \\
\hline
\end{tabular}

Halley-Chebyshev method has better performance than other methods

\section{Example2}

Consider the equation $f(x)=2 x^{3}-4 x+5 \cos x$. This function has a single root with accurate amount 1.472154984. In order to find a root close to $x=-1.472154984$, we let $x_{0}=0$. The obtained results by Newton iteration, new hybrid iteration [3], and Halley method [11] are presented in the under table. (Table 2 with $\varepsilon=10^{-1000}$ )

\section{Table 2}

\begin{tabular}{lcc}
\hline Methods & $\begin{array}{c}\text { The numbers of } \\
\text { iterations }\end{array}$ & $\begin{array}{c}\text { approximate } \\
\text { solution }\end{array}$ \\
\hline Newton method [1], [2], [6], [8], [9] and [10] & 65 & -1.472154984 \\
\hline Hybrid method [7] & 9 & -1.472154984 \\
\hline New Hybrid method [3] with $\omega=0$ & 6 & -1.472154984 \\
\hline New Hybrid method [3] with $\omega=0.35$ & 9 & -1.472154984 \\
\hline Chebyshev method [12] & 30 & -1.472154984 \\
\hline Halley method [11] & 18 & -1.472154984 \\
\hline Steffenson method [1] & 36 & -1.472154984 \\
\hline Halley-Chebyshev method [4] with $\omega=0.35$ & 14 & -1.472154985 \\
\hline
\end{tabular}

Halley-Chebyshev method has better performance than other methods

\section{Conclusions}

In this paper, we compare several iteration formulas to solve the roots of the nonlinear equations. Tables and results show that Halley-Chebyshev method has better performance than other methods. It can be seen from the examples that the current method is enough a faster method that takes lesser number of iterations, needs lesser number of functional evaluations in final as well as in individual step as compared to the other methods. 


\section{References}

1. Atkinson, Kendall E. An introduction to numerical analysis, John Wiley \& Sons, (1988).

2. Cheney .E .W, Kincaid .D, Numerical mathematics and computing, Thomson Learning, 2003.

3. Eskandari, Hamideh. "A New Numerical Solving Method for Equations of One Variable." World Academy of Science, Engineering and Technology 44 (2008): 196-199.

4. Hamideh Eskandari. A Novel Iteration Class for Solution of Nonlinear Equation. AmericanJournal of Applied Mathematics.Vol. 2, No. 5, 2014, pp. 186-190. doi: 10.11648/j.ajam.20140205.1

5. Fang .T, Fang .G, Lee .C.F, A new iteration method with cubic convergence to solve nonlinear algebraic equations, Applied Mathematics and Computation, 175 (2006) 1147-1155.

6. Hildebrand .F.B, Introduction to numerical analysis, Tata McGraw-Hill, (1974).

7. Nasr-Al-Din Ide, A new hybrid iteration method for algebraic equations, Applied Mathematics and Computation 195 (2008) 772-774.

8. $\quad$ Quarteroni .A, Sacco .R, Saleri .F, Numerical Mathematics, Springer, 2000.

9. $\quad$ Stewart .G .W, after notes on numerical analysis, SIAM, 1996.

10. Stoer .J, Bulirsch .R, Introduction to numerical analysis, Springer-Verlag, (1983).

11. Jisheng Kou, Yitian Li, Xiuhua Wang, On modified Newton methods with cubic convergence, Applied Mathematics and Computation, 176 (2006) 123-127.

12. Jisheng Kou, Yitian Li, Xiuhua Wang, A uniparametric Chebyshev-type method free from second derivatives, Applied Mathematics and Computation, 179 (2006) 296-300. 